\title{
An Exploratory Agent-Based Modeling Analysis Approach to Test Business Models for Electricity Storage
}

\author{
Seyed Ahmad Reza Mir Mohammadi Kooshknow ${ }^{1, * \mathbb{C}}$, Rob den Exter ${ }^{2}$ and Franco Ruzzenenti ${ }^{1}$ \\ 1 Energy and Sustainability Research Institute Groningen, University of Groningen, 9747 AG Groningen, \\ The Netherlands \\ 2 Stored Energy, 3125 BN Schiedam, The Netherlands \\ * Correspondence: s.a.r.mir.mohammadi@rug.nl
}

Received: 14 February 2020; Accepted: 25 March 2020; Published: 2 April 2020

check for updates

\begin{abstract}
Electricity storage systems (ESSs) are potential solutions to facilitate renewable energy transition. Lack of viable business models, as well as high levels of uncertainty in technology, economic, and institutional factors, form main barriers for wide implementation of ESSs worldwide and in the Netherlands. Therefore, the design of business models for an ESS is necessary for the development of ESSs. We elaborated on this problem before, and developed a design space for business models of ESSs in the context of the Netherlands. This conceptual paper provides a further view on barriers and uncertainties of ESS development in the Netherlands through the involvement of a business practitioner, elaboration of goals, objectives, and testing of ESS business model designs, suggests and provides a theoretical foundation for combining agent-based modeling and exploratory modeling analysis as a method to test and explore ESS business models, and provides an abstract conceptual agent-based model design thereof. This work can be used as a foundation of detailed design and implementation of models for testing ESS business models in the Netherlands and worldwide.
\end{abstract}

Keywords: electricity storage system; business model test; agent-based modeling; exploratory modeling analysis

\section{Introduction}

Electricity storage systems (ESSs) are among the suggested solutions to manage the variability of renewable energy productions and stability of grids. Despite the potential of ESS, the implementation of ESSs worldwide (except pumped-hydro storage) is still small in size due to technical, institutional, and economical challenges [1,2]. Power system flexibility can be defined as "the extent to which a power system can adapt electricity generation and consumption as needed to maintain system stability in a cost-effective manner" [3]. The stability of the system can be maintained if we guarantee that the volume of supply and demand is equal at all locations and at every moment in time. An ESS is capable of solving the problem of mismatches in time of generation and consumption section of the power system as it is capable of keeping already-generated electricity and re-generating it at better times. Therefore, on the generation side, an ESS can help to manage problems of variable generation such as wind generation by providing a firm output. Across the grids, an ESS enables peak shaving by discharging electricity near heavily loaded points. In addition, it enables the arbitrage of electricity among various markets for electricity and its services. Moreover, at the consumer side (behind the meters), an ESS helps to manage the time-of-use of electricity for cost reduction. We can find three general sets of global challenges for the development of ESSs. The first set of challenges are technical 
challenges. The development of technologies suitable for desired applications is a challenge as no ES technologies are currently suitable for all applications. In addition, most current ES technologies are still under development and they are not matured yet. The second challenge is the low penetration of variable renewables in the electricity systems. In [1], we highlighted that with a low share of variable renewables, variations can be solved by the grid or cheaper flexibility solutions, and we explained that the current energy portfolio in the Netherlands, which consists of a high share of natural gas and coal, does not motivate solutions such as an ESS to offer flexibility to the market. The third set of challenges includes economic and business challenges. Here, the first challenge is the high costs of ESS, and in turn, the high levelized cost of energy (LCOE). The fact that most ES technologies are not matured yet partially justifies the high cost of ESS. The ability of an ESS for competing with other solutions of power system flexibility, such as cheap demand response, puts ESSs under question. In addition, a lack of viable business models, as well as uncertainty and unsupportiveness of regulatory frameworks, are barriers of development for ESSs [4-6]. Thus, developing business models for ESSs could improve the market penetration of incumbent ES technologies and increase their economic scaling up, with a positive feedback on both production costs and the marketability of renewable energy. Arguably, good business models (third challenge) could lead to a positive feedback loop on two fronts: increasing the economy of scale for ESSs (first challenge) and expanding market share of renewables (second challenge). This is why we deem it to be of paramount importance to effectively approach the lack of business models as a possible, viable solution to unlock the potential of ESSs and exit the current stalemate.

In previous work, institutional challenges and business model design alternatives for ESSs in the Netherlands have been examined [1]. A business model describes "the rationale of how an organization creates, delivers, and captures value" [7]. To design business models, it is necessary to define business goals, identify business model alternatives, develop tests, and select among the alternatives using tests. While in the previous work we developed a design space as a set of alternatives, the objective of this paper is to elaborate on the goals, objectives, and constraints and the involved uncertainties, as well as analysis and selection of testing methods for an ESS business model design, by means of a combination of agent-based modeling (ABM) and exploratory modeling analysis (EMA). In doing so, we benefited from the collaboration with a practitioner of the ESS business in the Netherlands who is also the co-author of this paper.

In Section 2, we will elaborate on ESS business challenges and uncertainties in the Netherlands. Identifying uncertainties is critical for the design and development of business models. In Section 3 , we will have a generic view on a design process, and its meaning for designing business models. We will explain the goals, objectives, and constraints for designing business models, as well as considerations for testing business models. Then, in Section 4, we will outline how to combine ABM and EMA as a suitable approach for testing ESS business models. In addition, we will provide an abstract conceptual design for such a test. Finally, in Section 5, some conclusions will be drawn.

\section{ESSs in the Netherlands: Status Quo Analysis}

Organizations with an interest in energy storage technology tend to approach their investment decision from an operational point of view. Mainly, they are interested in how energy storage can lower their energy bill or solve operational constraints.

\subsection{Products, Services, and Value Propositions}

ESS offer organizations the opportunity to lower their energy bills. To some extent this is possible due to increased self-consumption of generated solar energy. Instead of feeding excess energy back into the grid for a low fee, the energy can be stored and used when necessary. However, due to the relatively low energy prices per $\mathrm{kWh}$ in the Netherlands compared to the high cost for the ESS, this is not yet a viable business model. 
A second and more promising application is peak shaving. A behind-the-meter ESSs can act as a buffer and reduce peak demand at the connection point. This reduces charges from the grid operator. This application becomes more relevant with increased electrification of facilities, e.g., due to increased demand for EV-charging. Already, there are some viable business cases in certain demand ranges [8,9].

Third, an ESS can be used to benefit from the ancillary services and the associated balancing markets. Especially, the revenue that can be unlocked in the market for primary reserve (FCR) has been the most significant driver of the business case for most large scale ( $>1 \mathrm{MW})$ energy storage projects in the Netherlands. However, there is only a limited demand for these services from the TenneT transmission system operator (TSO), which has resulted in quite a decline in average weekly revenues over the last few years [10].

Fourth, ESSs are used as a source of emergency or mobile power. Increasingly, ESSs are suitable as a realistic replacement for conventional diesel-powered generators. More stringent norms and legislation for $\mathrm{CO}_{2}$ and $\mathrm{NOx}$ emissions are driving companies to search for alternatives. Additional benefits are low noise and no fumes that are generated compared to diesel generators. Still, there are challenges from an operational point of view, since the energy capacity and power output per Euro invested in an ESS is quite high compared to diesel gen-sets.

Combining a few of the above-mentioned applications of ESSs is key for financial viability. Only then, an ESS is used to its full potential. Large projects at the Amsterdam Arena or Cars Jeans Stadion have both succeeded because of this so-called revenue stacking. Though, both projects have also been subsidized to some extent, to close the financial gap.

\subsection{State of the Art}

From a technology point of view, lithium-ion $\left(\mathrm{LiNiMnCoO}_{2}\right.$ and $\left.\mathrm{LiFePO}_{4}\right)$ - based systems have been dominant. The value chain is dominated by a relatively small amount of cell manufacturers, power conversion system manufacturers and system integrators. Lithium-ion based systems tend to offer the lowest LCOE in most use cases. Also, the technology offers attractive technical characteristics, such as energy density and rate of (dis)charge [11,12].

In the Netherlands, the market for energy storage is still in the introduction phase. No official data of ESS-installations are tracked by authorities. Estimates, however, based on the EnergystorageNL database [13], reveal that there have been less than 10 large-scale (>1 MW) ESS installations, and about 15 medium-scale (100 kW-1 MW) projects. Smaller-scale projects, amongst home batteries, are estimated at about 500 installations. In Germany, the market is more mature with every second residential PV-installation being complemented with a home battery. Estimates are that there are now more than 120,000 (home) batteries in Germany [14].

Most large- and medium-scale projects in the Netherlands have received some kind of subsidy (local, national or even European) [15]. Without these subsidies, most projects are not viable from a financial point of view.

\subsection{Technology Potentials}

Downsides of lithium-ion based ESSs are the dependency on (rare) earth materials, lack of a recycling industry, limited lifespan and limited potential for large scale seasonal energy storage. Other technologies are expected to complement lithium-ion based systems, resulting in various energy carriers that are co-existing.

Most promising as an energy carrier is hydrogen. The variety of applications, high energy density (when compressed or liquefied) and scalability makes it a key storage technology. Combined with a fuel cell and hydrogen storage tank, a hydrogen-based ESS has the potential to be a very relevant asset in future energy storage markets. As of now (early 2020), these systems tend to be far too expensive for commercial applications. In particular, the cost of electrolysers that are needed to convert electricity to hydrogen, as well as the cost of fuel cells, need to drop significantly [10]. 
Vanadium redox flow batteries are slowly entering the markets. They offer the opportunity of storing energy in non-toxic, non-hazardous fluids, and consist of widely available elements. A long lifespan is promised, as well as the opportunity to fully discharge the ESS (li-ion based systems can discharge up to $90 \%$ ). As of early 2020, about 5-10 companies were ready to offer such systems in the Netherlands. The costs are still quite high compared to lithium-ion based systems, and performance characteristics such as c-rate and energy density cannot yet compete with lithium-ion ESSs.

Finally, quite a few other technologies are becoming commercially available. Amongst others, there are salt-water batteries and nickel-iron batteries that are showing promising value for money. In all cases, further scale-up and mass production will be necessary to fully benefit from these technologies.

\subsection{Barriers for ESS Development}

The main constraint in the Dutch market for energy storage is that there is no urgency for the implementation of the technology. The grid is very reliable, with power outages of less than $0.1 \%$ of the time per year. So far, the penetration of renewables in the energy mix is quite low, which makes it still relatively easy for grid operators to include renewable energy in the grid. Therefore, the value of the flexibility that can be provided by ESSs is not yet acknowledged by market mechanisms (for more details, see [1]).

Despite significant price drops for lithium-ion cells in the past 10 years, batteries are still quite expensive, especially when compared to the cost of solar panels or wind turbines that they are supposed to complement. Prices range from $€ 500-€ 1.000$ per kWh installed, with significant economies of scale being present. For example, a $500 \mathrm{kWh}$ system requires a CAPEX of about $€ 375,000$. If an investor would put such an amount in a solar array, there is a predictable cash flow and payback period. Investing in ESSs is, from an investor's perspective, much riskier since the cash flow is very uncertain [6].

Subsidies helped to kick-start the market for ESSs. In order to receive some kind of subsidy, the innovative application of ESSs are required by most authorities. Thus, there is no consistent subsidy in place that can always be applied by investors in ESS equipment. This makes it harder for new projects to obtain subsidy since most demonstrations of ESS-applications have been subsidized already.

Finally, there are constraints from a legal point of view. Norms and standards are still under construction [16], resulting in unclear procedures on how to assess safety issues by, for instance, fire departments or insurance companies.

\subsection{Uncertainties}

The uncertainties concerning the ESS business can be classified into four groups. Legal uncertainties are the first group of uncertainties. The rules and regulations of ownership of ESSs, and the safety of some electricity storage technologies provide challenges for ESS business. The second group of uncertainties are the fiscal framework, as there is no clear view on the development of subsidies or tax schemes. Technical uncertainties form the third group of uncertainties. The development of new ES technologies and their technical characteristics such as lifetime and maintenance, as well as the integration of the ES technologies to the grid can influence the ESS business. Last but not least, market uncertainties are inherent uncertainties in most businesses as the supply, demand, and prices in ES market, electricity market and balancing market are uncertain.

The status quo analysis for ESS business in the Netherlands, indicates that not all possible applications of ESSs received attention due to economics, technical, or legal challenges. Business model innovation could be a key to overcome the current barriers and unlock the potentials of ESS. In the following sections, we will outline an approach for designing a business model under deep uncertainties.

\section{Design Process for Business Models of ESS}

Designing business models is required in order to overcome some ESS business challenges. Osterwalder \& Pigneur identified four general goals for business model innovation [7]: (1) satisfying 
existing but unanswered market needs; (2) bringing new technologies, products, or services to market; (3) improving, disrupting, or transforming an existing market with a better business model; (4) creating an entirely new market. For ESS, the main requirement can be considered as to enter and sustain in the market (goal 2) because an ESS is not part of the market yet. Transforming the current electricity market to a more flexible one (goal 3) could be the next goal of ESS business model innovation.

Similar to any other design project, certain steps should be followed for designing business models. Figure 1 illustrates a generic conceptual framework for design. The framework includes five main steps: (1) determine goals, (2) determine objectives, (3) determine constraints, (4) develop design space, and (5) tests for goals. In this framework, objectives are goals that need to be optimized, constraints are the binary goals to be met, and the design space illustrates a set of variables and components. In this framework, test means to determine to what extent the objectives and constraints are met by a design [17].

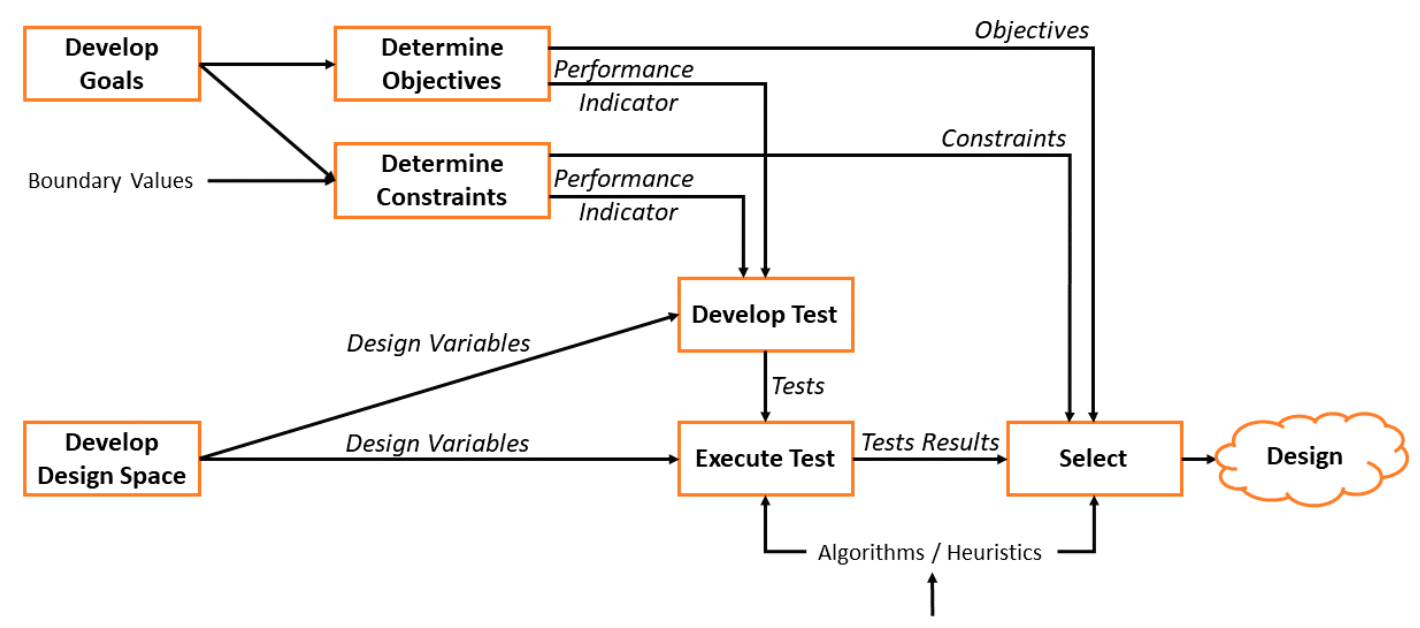

Figure 1. Generic design process reproduced from [17].

We previously covered some steps for designing business models for ESSs in the context of the Netherlands in [1] where we developed a design space (including a map of single-application business models for ESS) and we identified some constraints such as institutional, technical, and location constraints. In this paper, we follow up the design process by elaborating on goals, objectives, constraints, and the development of tests.

\subsection{Goals, Objectives, and Constraints}

Most successful designs, in various domains, share certain goals. A framework originally developed at IDEO, a global design company, indicates that successful designs provide balance among three generic goals of (1) feasibility, (2) viability, and (3) desirability [18]. For the process of business model design, feasibility indicates whether it is possible to provide a product or service, desirability indicates whether customers will value (or pay for) the products or services, and viability indicates whether a business is financially sound. In addition to these three criteria, it is necessary for business models to conform to external conditions in the environment such as legal conditions, macro-economic situations, etc. Therefore, another goal for a successful business model can be framed as "adaptability" [19].

The design goals need to be translated into measurable objectives and constraints to be optimized and met, respectively. In economic terms, the primary objective of a firm is maximizing its profit and other objectives finally serve this primary objective [20]. Profitability is a measure of the economic viability of business models. In addition, feasibility of business models for ESSs mainly depends on the well-functioning of the ESS devices and technology for target products. In the business or 
policy modeling, ESSs are considered as black boxes with aggregated parameters such as capacity, power rating that influence the transformations of inputs to outputs. Such parameters directly or indirectly influence or limit the operation, and in turn, the profitability of ESS. In analyzing the business model of ESSs, technical feasibility and its relevant considerations can be considered as assumptions or hypotheses of the business model. Furthermore, the desirability of business models depends on the number of customers who are willing to pay for a product or a service. Higher desirability in a business model design influences the profitability of the model. Therefore, similar to feasibility, desirability can be considered as an assumption that influences economic viability. Finally, the adaptability of business models influences all other goals. It may limit the desirability, feasibility, and viability of the business models. Figure 2 illustrates the causal/limiting relationships among the four aforementioned goals.

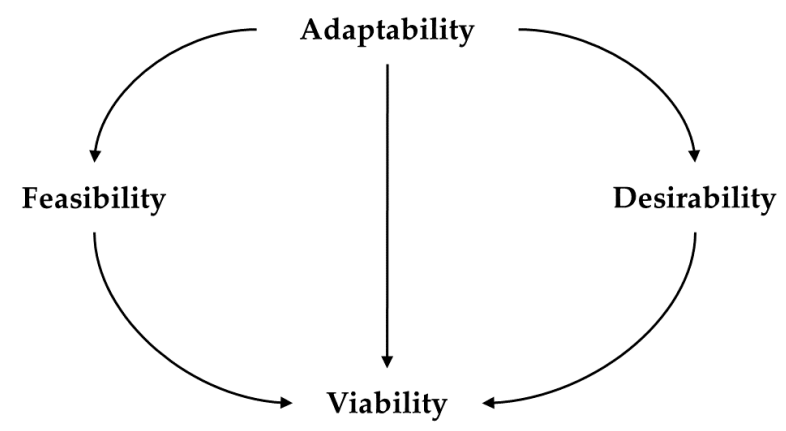

Figure 2. Relationship among the goals of business model design.

\subsection{Developing Tests for Business Models}

\subsubsection{Meanings of Business Model Test}

Tests of business models have some differences with engineering tests. In a generic design process framework (see Figure 1), testing a design involves measuring to what extent the design meets the objectives and constraints of the design and it needs to be done before selecting the final design. The test is done either on a prototype (computer simulation or material artifact) or on a complete product, depending on the test expenses. The meaning of a test in engineering designs seems to be very straight forward, however in the business model innovation literature, testing is not only about checking whether a business idea works and meet the goals, but it is also about checking if the business hypotheses (things need to be true for an idea to work but have not been validated yet) are valid [21,22]. In engineering designs, assumptions about many physical forces and characteristics are already validated in the natural sciences, but many assumptions in the business model designs still need to be validated. Therefore, testing business models are more or less about validating their assumptions.

\subsubsection{Directions of Business Model Test}

Four design goals for business models provide directions for testing them as well. It is possible to relate elements of business models to each direction. In our previous work, we elaborated on some design variables for ESS business models in the context of the Netherlands in which those elements were mostly selected from Business Model Canvas (BMC) [1]. BMC is a popular framework for analysis, design, and communication of business models. BMC contains nine blocks to illustrate the elements of the business models and their relationships [7]. Figure 3 illustrates the relationship between business model elements and directions of business model tests. The goal, "desirability", can be explored through BMC blocks of "customer segments", "customer relationships", "channels" and "value proposition"; the goal "feasibility" can be explored through BMC blocks of "key resources", "key activities", and "key partners"; and the goal "viability" can be explored through BMC blocks "cost structure" and "revenue streams" $[19,23]$. Finally, the goal adaptability can be explored through the analysis of the business model environment [19]. 


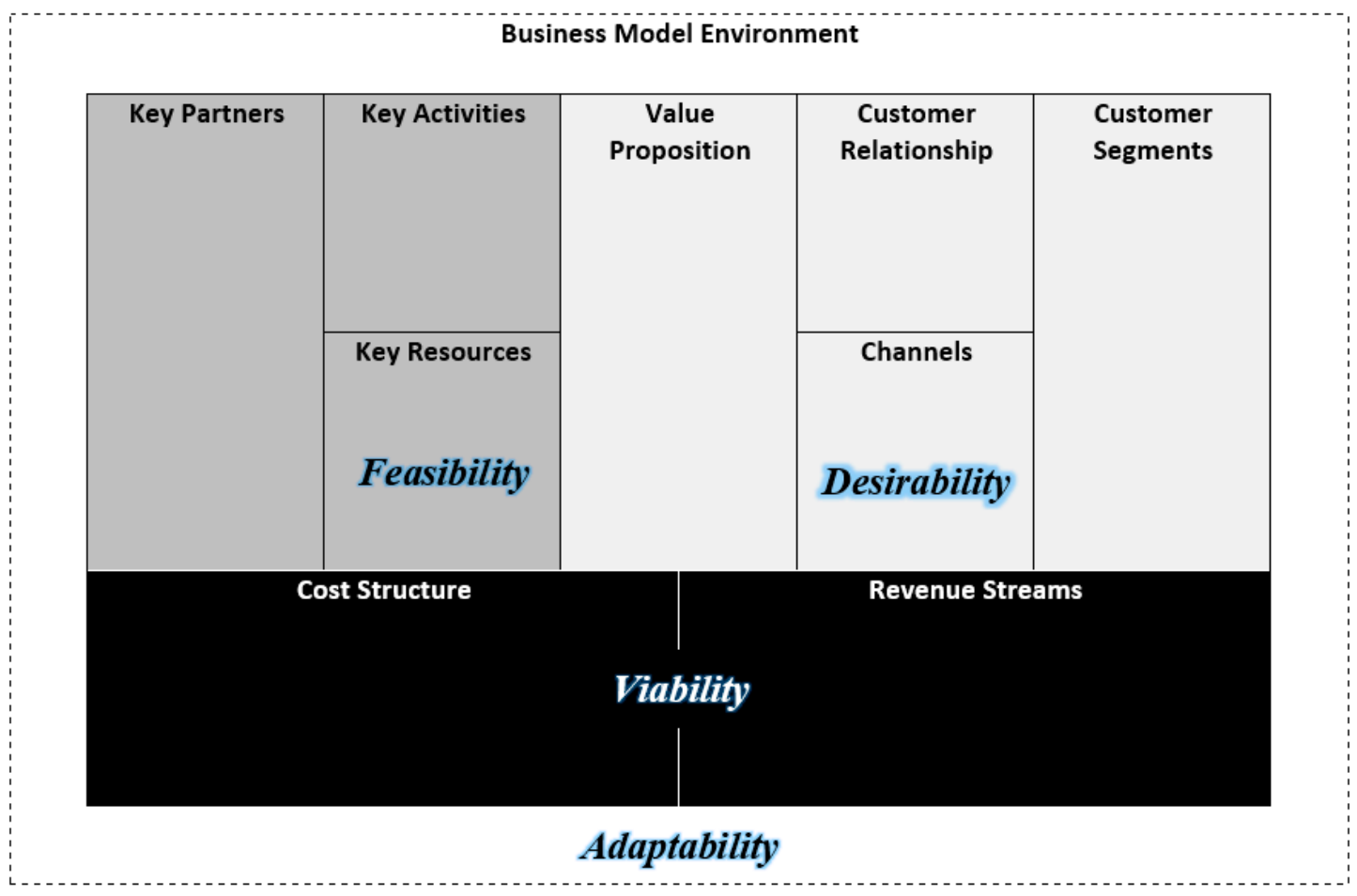

Figure 3. Relationship between business model elements and directions of business model test $[19,23]$.

\subsubsection{Yellow Hat before Black Hat}

The directions of a test come with a question on their weight and priority. Engineers and product developers may tend to think about a business by looking first at its technical feasibility, whereas the most important direction for investors is viability and the economic calculations. On the other hand, businesspeople prioritize desirability and market considerations arguing that "for every one of our failures, we had spreadsheets that looked awesome" [22], and policymakers may focus only on the adaptability of a business as they usually have no direct interest in the business.

It is wise to investigate the advantages of new ideas before analyzing their disadvantages. Edward de Bono in his book "six thinking hats", in which directions of effective thinking are represented by six colored hats, maintains that:

"In an assessment situation, it makes sense to put the yellow hat (hat of benefits and value) before the black hat (hat of caution and critics). If, under the yellow hat, you cannot find much value to the idea, there is no point in proceeding further. On the other hand, if you find much value under the yellow hat and then proceed to the black hat and find many obstacles and difficulties, you will be motivated to overcome the difficulties because you have seen the benefits. But if you start off by seeing all the difficulties, then your motivation is totally different [24]."

The interdependence of business model design goals (see Figure 2) reveals the fact that the viability of a business model depends on the other goals. If we seek to identify the advantages of business models before disadvantages, we can explore the potential benefits on the viability side. If there are not attractive or no potential benefits, it will not make sense to continue testing the assumptions of the other test directions.

\section{Modeling for Testing ESS Business Models}

Models may help business designers to test several assumptions of viability for business models. If models illustrate that there will be "hopes" for sustainable profit, further tests on other directions can be conducted to reduce risks to the business. In addition, lessons of modeling activities may provide insights on weights, importance, and priority of tests on the other directions. 


\subsection{Modeling Approach}

\subsubsection{Model Requirements}

A model for exploring and testing ESS business models must meet several requirements. First of all, the model should represent the electricity and services markets in terms of complex socio-technical systems. Therefore, it needs to entail several and diverse social and technical components. Second, the model should be capable of demonstrating co-evolution of the markets and ESSs as they are expected to influence each other. Third, the model should enable the analyst for ex-ante analysis of the effects of scenarios and policies under deep uncertainty as there is little information on various aspects of ESSs as a new solution in the market.

\subsubsection{Exploratory Modeling Analysis (EMA)}

Developed by Bankes in the RAND Corporation in 1990s, Exploratory Modeling and Analysis (EMA) is a research methodology that employs computational experiments to study systems by systematic exploration of the consequences of uncertainties, including uncertainties in parameters, structures, or methods [25-27]. EMA contrasts with "consolidative modeling" in which a model is built by consolidating known facts into a single best-estimate set and is used as a surrogate for the real system [25].

An initial point and a driver in the development of EMA was admitting that using models as surrogates of the real-world systems was not always possible $[25,28,29]$. In the presence of barriers to experimental validation, significant uncertainties, or strong non-linearity, outcomes of consolidative modeling are rather poor and unreliable $[25,29,30]$.

EMA is a solution for coping with the significant uncertainties, which are presented in the literature under various names such as deep uncertainty or sever uncertainty [27]. Deep uncertainty can be described as a situation in which analysts or decision-makers do not know or cannot agree on the appropriate conceptual models, the probability distribution of uncertain variables and parameters, and valuation of alternative outcomes [31]. In another view, it can be described as a situation in which the researcher is "being able to enumerate multiple alternatives without being able to rank order the alternatives in terms of how likely or plausible they are judged to be" [32]. This definition of deep uncertainty applies to several aforementioned uncertainties in Section 2. EMA copes with such uncertainties by conducting extensive computational experiments and calculating the outcomes of a set of plausible models, which is formed by varying assumptions, parameters, and methods [25,28].

Contrary to consolidative modeling, EMA not only can be used to answer, "what if" questions, but it can also answer questions such as "under what conditions a behavior may occur?", and "what are the plausible future dynamics in a phenomenon?" [27].

The EMA process consists of the following steps [33]: (1) conceptualization of the decision problem and the associated uncertainties, (2) development of a set of simple models, (3) specification of the targeted uncertainties, (4) analysis of the behaviors and model outcomes, (5) identification of the combinations of uncertainties which results in interesting behaviors, (6) assessment of model quality under the combinations of uncertainties, and (7) qualitative or quantitative communication of the typical futures from the combinations of interest.

EMA can be applied to several modeling paradigms, such as systems dynamics, agent-based modeling, etc., [27]. In this work, we suggest agent-based modeling as an appropriate paradigm to explore and test business models.

\subsubsection{Agent-Based Modeling (ABM)}

Agent-based modeling (ABM) is a computational modeling paradigm that enables us to describe how an agent will behave in a controlled environment [34]. In this paradigm, an agent is a "thing that interacts with other things" [35,36]. An agent-based model creates "an artificial world of heterogeneous 
agents and enables investigation into how interactions between these agents, and between agents and other factors such as time and space, add up to form the patterns seen in the real world" [37].

An agent-based model consists of agents, an environment, and interactions among agents or agents and the environment [34]. Agents are autonomous and encapsulated entities situated in a particular environment, they have goals and are capable of flexible actions. They have states (also called properties, attributes, etc.), internal rules for change of the states, and actions and behaviors. Agents can take actions that influence either themselves, other agents, or the environment. An environment is a place in which agents live, and it contains information, structure, and time (the latter can be either considered as part of the environment or an independent element of the whole model) [36].

Agent-based modeling is one of the best modeling approaches to model complex adaptive systems [36]. Among several modeling paradigms to study complex systems, ABM makes a better predictive approach as (1) it enables the capture of more complex structures and dynamics, (2) it makes the study possible even in absence of global interdependence data, and (3) it is easier to maintain and evolve [38]. Generally, ABM is applicable for studying systems if (1) the problem has a distributed character, (2) the sub-systems (can be elements, components, agents, etc.) in the study operate in a highly dynamic environment, and (3) the sub-systems have to interact in a flexible way $[36,39]$.

Therefore, $\mathrm{ABM}$ is a powerful paradigm for the studying and the evaluation of electricity storage business models considering the distributed control across the electricity systems and markets, the inherent dynamics (in demand, supply, prices, weather, rules, and regulations, etc.), and the increasing importance of flexibility in current and future electricity systems.

\subsubsection{Exploratory Agent-Based Modeling Analysis}

In this research, we suggest a combination of agent-based modeling and exploratory modeling analysis to address business model design for ESSs for a number of reasons. First of all, this combination provides the best fit to the model requirements that we elaborated on earlier in this section. Most current studies on the economics of an ESS talk about business cases and they adopt static models with several assumptions about external factors of a business (e.g., [40]). Using exploratory modeling analysis, we incorporate more external factors and their underlying (deep) uncertainties in our analysis.

Moreover, most current models cannot capture the dynamics, randomness, or even chaos in a variable, such as electricity market price, whereas agent-based models can easily capture such phenomena. In addition, the electricity market price is not only influenced by the existence and performance of ESSs on the market but also influences the economics and existence of ESSs. Many static models for evaluating the economics of projects cannot capture such a feedback loop, whereas this will be easily possible in the ABM.

Last but not least, despite the potential of EMA to provide researchers with insights on business model problems, to our knowledge this approach has not been adopted for such a purpose yet. Adoption of such an approach can not only lead to interesting results, but it can also come with surprises that pave a path for future research.

\subsection{Agent-Based Model Design to Test ESS Business Models}

To explore and test business model designs for ESSs, we consider the following organization for our research model.

\subsubsection{Agents}

Agents can be classified into two groups of institutional agents and physical components. Institutional agents may make commercial decisions whereas physical components make no decision and they follow rules of physical operations. The decision-making agents in the model are energy companies, end consumers, markets and the transmission system operator (TSO). Physical components include power plants, loads, ESSs, transmission grid (T-Grid), and distribution grids (D-Grid). 


\subsubsection{Interactions}

Interactions within the model (in the form of agent-agent and agent-environment) include:

- Control (right of utilization or ownership of physical components by institutional agents)

- Supply contracts (contract between institutional agents and end consumers to supply of end consumers)

- Wires (physical delivery of electricity)

- Information (message transfer among institutional agents)

- Payment links (cash flow among institutional agents)

\subsubsection{Model Environment}

The environment of the model has a network structure in which agents are nodes and interactions form links among the nodes. Modeler initializes the model by defining the number and type of agents and the interactions among them.

TSO is connected to T-Grids through links. Energy companies may be connected to power plants or ESSs through control links if they enact a power producer role, or they can control no physical component if they enact only a retailer role. Large consumers are connected to large loads via control links, while they may control ESSs as well. Power plants, ESSs, large loads, and D-Grids are connected to a T-Grid via wire links. In addition, small loads are connected to D-Grids via wire links. The market agent is connected to TSO, energy companies, and large consumers via information links. There are also payment links from the market to the energy companies and large consumers.

The spatial location of agents is not relevant to the present modeling approach (a further modeling requirement could include the physical sustainability of a grid's balance according to the geographical location of loads, distributed/centralized generations and transmission network, leading to a spatially embedded ABM). The model can run for years, where each year is represented by 288 time-steps to capture the dynamics over $24 \mathrm{~h}$ along 12 days (representing 12 months) and enable the modeler for inter-temporal analysis.

\subsubsection{Agent's Actions and Behaviors}

The model environment publishes the weather forecasts and fuel price data.

Energy companies and large consumers make decisions and a plan of electricity generation or consumption (also charge and discharge of ESSs) and make offers or bids to the wholesale and balancing markets. The market agent collects all offers and bids through information links, it clears the wholesale market and specifies the market price and accepted volumes, and it communicates the market results to the market participants. The market also publishes $\mathrm{CO}_{2}$ certificates and prices based on the collected bids. The agent market collects electricity payments from buyers and transfers electricity revenue to the seller via payment links. The agent market also sends a balancing bid ladder to TSO for later use.

Energy companies and large-scale consumers send orders of execution of generation or consumption through the control links towards physical components including power plants, ESSs, and large loads. At the same time, small loads start to consume or generate electricity (if micro-RES is attached). Physical components deliver electricity to or receive electricity from the connected grids.

If an imbalance occurs in the T-Grid, the T-Grid sends a signal to the TSO about the location and volume of imbalances through control links. TSO selects some energy companies or large consumers according to the bid ladder to provide balancing energy and notify them through the market agents. Then, the notified balancing parties adjust their generation or consumption to balance supply and demand in the grids. TSO asks the market to fine the parties with balancing deviations and pay parties who provided balancing energy. The market collects the fines and sends the balancing revenues through payment links. 
The model environment calculates carbon emissions. The market also collects $\mathrm{CO}_{2}$ payments and fines the parties with extra $\mathrm{CO}_{2}$ emission and collects the fines through money links.

The model environment calculates and updates the statistics of electricity generation and consumption, and financial status of institutional agents.

The experiments will explore the effects of different business models designs on the profitability of economic agents, $\mathrm{CO}_{2}$ emissions in the whole model, and reliability of the whole system under uncertainties in technologies and energy resources, fuel prices, demand, weather, and regulations.

\subsubsection{Relationship between the Agent-Based Model and Business Models}

As mentioned earlier, the business model is "the rationale of how an organization creates, delivers, and captures value" [7]. Therefore, business models can be encoded in an agent-based model by defining a set of states, rules, behaviors, and interactions for agents that represent commercial organizations. For example, for an agent that represents an energy company, which owns an ESS for wholesale arbitrage:

- A value proposition such as electricity is a property of the agent;

- Customer segments may be composed of other agents that represent other energy companies, energy consumers, or an energy market operator (if it buys electricity on behalf of others);

- Channels to interact with customers may be composed of a set of links such as information exchange with a market operator or end consumer as well as a set of wire links for delivery of electricity to the customer;

- Key resources may be defined as physical entities (agents) connected to an agent via control links. They can also be defined as states/ properties of agents;

- Key activities may be translated to a set of internal behaviors of an agent as well as a set of interactions with other physical or institutional agents. Activities such as production, and ESS (dis-)charge are among key activities of the business models which are encoded as internal behaviors of the agent and influence its interactions with other agents;

- Revenue streams may be represented by incoming payment links from other agents (for compensation of the delivery of a specific product or service);

- Cost structure included costs calculated from internal behaviors of the agent and outgoing payment links to other agents or the environment.

\subsubsection{Experimentation Plan}

One advantage of agent-based modeling is that it enables modelers to look at a problem from various perspectives. Using the aforementioned model, one can see the problem from the perspective of an energy company by exploring and discovering the effects of the business model designs (independent variable of the research) on patterns of profitability of the energy companies (more specifically, the value of the company and NPV of ESS projects), as well as the green image of the company (e.g., its contribution to $\mathrm{CO}_{2}$ emission reduction). Similarly, the experiments from the perspective of policymakers will explore and discover the effects of various business model designs on the patterns of dynamics in electricity prices, $\mathrm{CO}_{2}$ emissions in the whole model, and reliability of the whole system (e.g., in terms of the number of blackouts) under uncertainties in technologies and energy resources, fuel prices, demand, weather, and regulations (which are the parameters of the model).

\section{Conclusions}

In this conceptual article, we provided a view on the testing of business models for electricity storage systems (ESSs). First, the current business perspectives on ESSs were explained and the necessity for designing new business models for ESSs was highlighted. Next, the design process for business models was elaborated on, where the meaning of a business model test was clarified, and directions of tests and their priority were introduced and discussed. Then, a combination of 
agent-based modeling (ABM) and exploratory modeling analysis (EMA) was suggested as a way of testing and exploring the economic viability of business models under various uncertainties of the market, technologies, and business environment.

The provision of a business perspective on ESS business uncertainties, analysis of the capability of ABM and EMA to test business models under deep uncertainty, and provision of an abstract agent-based model design were the main contributions to this paper. Implementation of the model and conducting business model test experiments will be the next step of our research.

Unless we expect that ESSs will be forcibly introduced or copiously funded by states, in a market economy, only viable business models can channel investors' money to ESSs and create the condition for their development. In the same vein, it is our convincement that deep uncertainties concerning the business space for ESSs represent a major bottleneck to the development of the full potential for ESS capacity, in the Netherlands and elsewhere. In a vicious circle, the lack of sufficient buffering capacity in the network is hindering the penetration of renewable energy as much as the insufficiency of renewable sources in the energy mix hinders the demand for ESSs. In this paper, we made a joint effort between academics and business to dissect the problem and envisaged a possible approach to theoretically tackle such uncertainties and facilitate the creation of new business models. Technology is under development and in some cases economical, business and institutional changes are the next steps to be taken, and we hope to contribute to this effort, with this and future work.

Author Contributions: Conceptualization, S.A.R.M.M.K. and F.R.; Methodology, S.A.R.M.M.K.; Formal analysis, S.A.R.M.M.K. and R.d.E.; Investigation S.A.R.M.M.K. and R.d.E.; Writing—original draft preparation, S.A.R.M.M.K., R.d.E. and F.R.; writing - review and editing, S.A.R.M.M.K. and F.R.; visualization, S.A.R.M.M.K.; supervision, F.R.; project administration, F.R.; funding acquisition, S.A.R.M.M.K. and F.R. All authors have read and agreed to the published version of the manuscript.

Funding: This research and the APC were funded by University of Groningen project code 190152210.

Conflicts of Interest: The authors declare no conflict of interest. The funders had no role in the design of the study; in the collection, analyses, or interpretation of data; in the writing of the manuscript, or in the decision to publish the results.

\section{References}

1. Mir Mohammadi Kooshknow, S.A.R.; Davis, C.B. Business models design space for electricity storage systems: Case study of the Netherlands. J. Energy Storage 2018, 20, 590-604. [CrossRef]

2. Aneke, M.; Wang, M. Energy storage technologies and real life applications-A state of the art review. Appl. Energy 2016, 179, 350-377. [CrossRef]

3. Papaefthymiou, G.; Grave, K.; Dragoon, K. Flexibility Options in Electricity Systems; Ecofys: Berlin, Germany, 2014.

4. Gallo, A.B.; Simões-Moreira, J.R.; Costa, H.K.M.; Santos, M.M.; Moutinho dos Santos, E. Energy storage in the energy transition context: A technology review. Renew. Sustain. Energy Rev. 2016, 65, 800-822. [CrossRef]

5. Anuta, O.H.; Taylor, P.; Jones, D.; McEntee, T.; Wade, N. An International Review of the Implications of Regulatory and Electricity Market Structures on the Emergence of Grid Scale Electricity Storage. Renew. Sustain. Energy Rev. 2014, 38, 489-508. Available online: https:/www.sciencedirect.com/science/article/abs/pii/ S1364032114004432?via\%3Dihub (accessed on 13 February 2020). [CrossRef]

6. DNV GL. Safety, Operation and Performance of Grid-Connected Energy Storage Systems. 2017. Available online: https://rules.dnvgl.com/docs/pdf/DNVGL/RP/2017-09/DNVGL-RP-0043.pdf (accessed on 13 February 2020).

7. Osterwalder, A.; Pigneur, Y. Business Model Generation: A Handbook for Visionaries, Game Changers, and Challengers; John Wiley \& Sons: Hoboken, NJ, USA, 2010; ISBN 9780470876411.

8. McKinsey \& Company How Battery Storage Can Help Charge the Electric-Vehicle Market. Available online: https:/www.mckinsey.com/business-functions/sustainability/our-insights/how-battery-storage-canhelp-charge-the-electric-vehicle-market\# (accessed on 13 February 2020).

9. ALFEN Shell Ultrafast EV Charging Service to Incorporate Alfen Energy Storage. Available online: https://alfen.com/en/news/shell-ultrafast-ev-charging-service-incorporate-alfen-energy-storage (accessed on 14 February 2020). 
10. van der Veen, A.; van den Noort, A.; Kranenburg-Bruinsma, K. Marktpotentie Groene Waterstof Productiefaciliteiten; DNV.GL, TNO: Groningen, The Netherlands, 2018.

11. Baker, D.R. Why Lithium-ion Technology is Poised to Dominate the Energy Storage Future. Available online: https:/www.renewableenergyworld.com/2019/04/03/why-lithiumion-technology-is-poised-todominate-the-energy-storage-future/\#gref (accessed on 14 February 2020).

12. Temple, J. Why Lithium-ion May Rule Batteries for a Long Time to Come. Available online: https://www. technologyreview.com/s/611982/why-lithium-ion-may-rule-storage-technology-for-a-long-time-to-come/ (accessed on 13 February 2020).

13. Energy Storage, N.L. Energieopslagprojecten in Nederland. Available online: https://www.energystoragenl. nl/projects (accessed on 7 February 2020).

14. Hockenos, P. In Germany, Consumers Embrace a Shift to Home Batteries-Yale E360. Available online: https:// e360.yale.edu/features/in-germany-consumers-embrace-a-shift-to-home-batteries (accessed on 7 February 2020).

15. GIGA STORAGE GIGA STORAGE VERSNELT DE ENERGIETRANSITIE MET DE KRACHTIGSTE BATTERIJ VAN NEDERLAND. Available online: https://giga-storage.com/2019/12/04/persbericht-giga-rhino/ (accessed on 13 February 2020).

16. PGS Veilige Opslag van Lithium-ion Batterijen. Available online: https://publicatiereeksgevaarlijkestoffen.nl/ nieuws/veilige-opslag-lithiumion-batterijen.html (accessed on 7 February 2020).

17. Herder, P.M.; Stikkelman, R.M. Methanol-Based Industrial Cluster Design: A Study of Design Options and the Design Process. Ind. Eng. Chem. Res. 2004, 43, 3879-3885. [CrossRef]

18. Brown, T. Change by Design: How Design Thinking Can Transform Organizations and Inspires Innovation; HarperCollins Publishers: New York, NY, USA, 2009; ISBN 978-0-06-176608-4.

19. Strategyzer Strategyzer Webinar: The Basics of Testing Business Ideas. Available online: https://www. youtube.com/watch?reload=9\&v=IFjZkRbXhiA (accessed on 18 June 2018).

20. Parkin, M. Microeconomics, 10th ed.; Pearson Series in Economics; Addison-Wesley: Boston, MA, USA, 2012; ISBN 9780131394254.

21. Osterwalder, A.; Pigneur, Y.; Bernarda, G.; Smith, A.; Papadakos, T. Value Proposition Design: How to Create Products and Services Customers Want; John Wiley \& Sons, Inc.: Hoboken, NJ, USA, 2014; ISBN 9781118968055.

22. Johnson, M.W. Seizing the White Space: Business Model Innovation for Growth and Renewal; Harvard Business Press: Boston, MA, USA, 2010; ISBN 1422124819.

23. Jeffries, I. Free eBook: Building A Strong Business Model. Available online: https://isaacjeffries.com/blog/ 2017/10/14/free-ebook-building-a-strong-business-model (accessed on 1 July 2019).

24. de Bono, E. Six Thinking Hats; Penguin Books Limited: London, UK, 2017; ISBN 9780241336878.

25. Bankes, S. Exploratory Modeling for Policy Analysis. Oper. Res. 1993, 41, 435-449. [CrossRef]

26. Bankes, S.; Walker, W.E.; Kwakkel, J.H. Exploratory Modeling and Analysis. In Encyclopedia of Operations Research and Management Science; Gass, S.I., Fu, M.C., Eds.; Springer US: Boston, MA, USA, 2013; pp. 532-537, ISBN 978-1-4419-1153-7.

27. Kwakkel, J.H.; Pruyt, E. Exploratory Modeling and Analysis, an approach for model-based foresight under deep uncertainty. Technol. Forecast. Soc. Chang. 2013, 80, 419-431. [CrossRef]

28. Agusdinata, B. Exploratory Modeling and Analysis: A Promising Method to Deal with Deep Uncertainty; Delft University of Technology: Delft, The Netherlands, 2008.

29. Walker, W.E.; Haasnoot, M.; Kwakkel, J.H. Adapt or perish: A review of planning approaches for adaptation under deep uncertainty. Sustainability 2013, 5, 955-979. [CrossRef]

30. Van Der Pas, J.W.G.M.; Walker, W.E.; Marchau, V.A.W.J.; Van Wee, G.P.; Agusdinata, D.B. Exploratory MCDA for handling deep uncertainties: The case of intelligent speed adaptation implementation. J. Multi-Criteria Decis. Anal. 2010, 17, 1-23. [CrossRef]

31. Lempert, R.J.; Popper, S.W.; Bankes, S.C. Shaping the Next One Hundred Years, 1st ed.; RAND Corporation: Pittsburgh, PA, USA, 2003; ISBN 9780833032751.

32. Kwakkel, J.H.; Walker, W.E.; Marchau, V.A.W.J. Classifying and communicating uncertainties in model-based policy analysis. Int. J. Technol. Policy Manag. 2010, 10, 299-315. [CrossRef]

33. Kwakkel, J.H.; Auping, W.L.; Pruyt, E. Dynamic scenario discovery under deep uncertainty: The future of copper. Technol. Forecast. Soc. Chang. 2013, 80, 789-800. [CrossRef]

34. Wilensky, U.; Rand, W. An Introduction to Agent-based Modeling: Modeling Natural, Social, and Enginered Complex Systems with NetLogo; MIT Press: Cambridge, MA, USA, 2015; ISBN 9780262731898. 
35. Shalizi, C.R. Methods and Techniques of Complex Systems Science: An Overview. In Complex Systems Science in Biomedicine; Deisboeck, T.S., Kresh, J.Y., Eds.; Springer US: Boston, MA, USA, 2006; pp. 33-114, ISBN 978-0-387-33532-2.

36. van Dam, K.H.; Nikolic, I.; Lukszo, Z. Agent-Based Modelling of Socio-Technical Systems; Springer Publishing Company, Incorporated: Dordrecht, The Netherlands, 2012; ISBN 10: 9400749325; ISBN 13: 9789400749320.

37. Hamill, L.; Gilbert, N. Agent-Based Modelling in Economics; John Wiley \& Sons: Chichester, West Sussex, UK, 2016; ISBN 9781118456071.

38. Borshchev, A.; Filippov, A. From System Dynamics and Discrete Event to Practical Agent Based Modeling: Reasons, Techniques, Tools. In Proceedings of the 22nd International Conference of the System Dynamics Society, Oxford, UK, 25-29 July 2004.

39. Van Dam, K.H. Capturing Socio-Technical Systems with Agent-Based Modelling; Delft University of Technology: Delft, The Netherlands, 2009.

40. Schroeder, A.; Traber, T. The economics of fast charging infrastructure for electric vehicles. Energy Policy 2012, 43, 136-144. [CrossRef]

(C) 2020 by the authors. Licensee MDPI, Basel, Switzerland. This article is an open access article distributed under the terms and conditions of the Creative Commons Attribution (CC BY) license (http://creativecommons.org/licenses/by/4.0/). 